\title{
Relation of personality factors and life events to waist/height ratio and percentage of visceral fat in women and men
}

This article was published in the following Dove Press journal: Psychology Research and Behavior Management

\author{
Milos Slepecky' \\ Antonia Kotianova' \\ Jan Prasko ${ }^{1,2}$ \\ Ivan Majercak ${ }^{3,4}$ \\ Michal Kotian ${ }^{5}$ \\ Erika Gyorgyova ${ }^{4}$ \\ Marta Zatkova' \\ Michaela Chupacova ${ }^{5}$ \\ Marie Ociskova ${ }^{2}$ \\ Tomas Sollar ${ }^{1,6}$ \\ 'Department of Psychology Sciences, \\ Faculty of Social Science and Health Care, \\ Constantine the Philosopher University \\ in Nitra, Nitra, The Slovak Republic; \\ ${ }^{2}$ Department of Psychiatry, Faculty of \\ Medicine and Dentistry, University \\ Palacky Olomouc, University Hospital, \\ Olomouc 77520, The Czech Republic; \\ ${ }^{3}$ Ist Department of Internal Medicine, \\ Faculty of Medicine, Pavol Josef Safarik \\ University in Košice, Košice, The Slovak \\ Republic; ${ }^{4}$ Internal Medicine and \\ Cardiology, Private practice MUDr Ivan \\ Majercak, Košice, The Slovak Republic; \\ ${ }^{5}$ Department of clinical psychology, \\ Psychagogia, Liptovsky Mikulas, 03I0I, \\ The Slovak Republic; ${ }^{6}$ Institute of Applied \\ Psychology, Faculty of Social Science and \\ Health Care, Constantine the \\ Philosopher University in Nitra, Nitra, \\ The Slovak Republic
}

Correspondence: Milos Slepecky Department of Psychology Sciences, Faculty of Social Science and Health Care, Constantine the Philosopher University in Nitra, Kraskova I, Nitra 94974, The Slovak Republic

Tel +42I 903500887

Email milos.slepecky@gmail.com
Purpose: The investigation aimed to explore the association between personality traits, stressful life events, quality of life on anthropometric characteristics (waist/height ratio and percentage of visceral fat).

Method: A total of 227 participants took part in this cross-sectional study. Participants completed the Social Readjustment Rating Scale (SRRS), Temperament and Character Inventory-Revised, Type-D Scale (DS-14), EuroQol Group 5-Dimension Self-Report Questionnaire (EQ-5D), and demographic questionnaire. Two anthropometric parameters were measured: Waist/height ratio and Percentage of the visceral fat.

Results: The average age of participants was $39.6 \pm 12.9$ years, $60.4 \%$ women. The $41.8 \%$ of participants were overweight or obese. Regression analysis found a significant link between Harm-avoidance and EQ-5D visual analog scale (VAS) with Waist/height ratio in women and Reward dependence and Cooperativeness with Waist/height ratio in men. In regression analysis, the score of life events (SRRS) has statistically significant linked to Percentage of the visceral fat in women. The regression analysis also found a significant link between Novelty seeking, DS14, Negative affectivity, and EQ-5D VAS with Percentage of the visceral fat in women.

Conclusion: Significant associations between live events, personality traits, and body anthropometric measures were recognized. The differences were recognized between women and men. Outcomes propose some promising tools by which personality factors may influence overweight and obesity.

Keywords: life events, personality traits, anthropometric characteristics, overweight, quality of life, negative affectivity, sex differences

\section{Introduction}

Stressful life events, personality traits, and quality of life could play a role in the development of obesity and metabolic syndrome that are associated with the risk of developing cardiovascular disease (CVD). ${ }^{1-3}$ It is supposed that higher body weight is associated with clinical CVDs even at moderate degrees as an independent risk factor. ${ }^{4-9}$ Being overweight (ie, Body mass index $>25 \mathrm{~kg} / \mathrm{m}^{2}$ ) or obese (Body mass index $>30 \mathrm{~kg} / \mathrm{m}^{2}$ ) are common, and they can be caused by various factors (eg, genetic, biological and psychosocial). ${ }^{10}$ Overweight and obesity have recently become a serious problem in developed countries. ${ }^{11}$ Obese individuals have a two-fold risk of heart failure and a 4.1-fold risk of CVD compared to individuals with normal weight. ${ }^{5}$ Many investigations have discovered a U-shaped association 
between Body mass index and CVD mortality, with the association being detected in all cultural groups and not being dependent on gender. ${ }^{12-14}$ However, Body mass index is a poorer predictor of CVD compared to measures of central adiposities, ${ }^{15,16}$ characterized by the distribution of visceral fat in the abdominal area. ${ }^{17-19}$ The development of abdominal-visceral obesity is associated with an increased risk of cardiovascular complications. ${ }^{20-22}$

\section{Body weight and stress induced by life events}

Results from a large Danish community sample show more emotional distress among underweight and obese individuals after adjusting for socio-demographic factors. ${ }^{23}$ Slepecky et al, ${ }^{24}$ compared the psychological, psychophysiological, and anthropometric factors connected with life events, depresivity, and quality of life of the 54 healthy participants and 45 patients with cardiovascular problems. ${ }^{24}$ Life events experienced in the last two years were an influential factor connecting with overweight. The experiences of distress were accompanying with increased Body mass index and waist circumference. ${ }^{25}$ Stress-related eating could intermediate the link between stress experiences and overweight. ${ }^{26}$ Stress activates the hypothalamic-pituitaryadrenal axis and sympathetic nervous system which leads to hormonal abnormalities including increased cortisol secretion and development of visceral fat. ${ }^{27}$ Surkan et al, ${ }^{28}$ studied how stressful life events and social support are related to central adiposity in Southern Brazil. Stressful life events predicted a change in waistline two years later in men and a change in both waist-to-hip ratio and waist circumference in women. The second way of how chronic stress could play a part in the expansion of fat is its effect on dietary eating, with the ingestion of high-energy nutrients. ${ }^{29-32}$

\section{Personality traits and body weight}

Obesity tends to be reflected as a chronic disease and therefore possibly interrelates with the person's most emphasized temperament and character qualities. Personality traits could impact the way of life. Consequently, certain personality qualities could contribute to overweight. ${ }^{33}$ Inborn personality traits can affect dietary eating and could be involved in the vulnerability to overweight and in the failure of overweight individuals to reach effective weight loss. ${ }^{34}$ Personality traits play a significant part both as hazardous as well as protective factors in the development of overweight and obesity. ${ }^{35-37}$ Whereas "sensitivity to reward", "impulsivity", and "neuroticism", look like as hazard features, "self-control" and "conscientiousness" have been having a protecting function concerning good weight control. ${ }^{38}$ Extraversion among males (high scores) and agreeableness among females (low scores) were the personality traits significantly related to the obesity when adjusting for duration of education in sizeable Danish midlife community sample. ${ }^{39}$

The Temperament and Character Inventory (TCI) was established to offer a complete personality assessment, its temperament, and character traits. ${ }^{40-42}$ The TCI measures seven dimensions of personality: (1) Novelty seeking, (2) Reward dependence, (3) Harm-avoidance, (4) Persistence, (5) Self-directedness, (6) Cooperativeness, and (7) Selftranscendence). It is supposed that each temperament domain has a unique genetic variance and is reproducible in general and clinical setting. ${ }^{41}$ The high score in Novelty seeking was linked with overeating, whereas a low score was related to a small need to eat and reduced food intake in eating disorders patients. ${ }^{43-47}$ Sullivan et al, ${ }^{33}$ test the hypothesis that personality traits differ among lean and obese persons. Compared with lean individuals, obese individuals scored higher in Novelty seeking, lower in Persistence, and lower in Self-directedness. Patients registered in the Washington University Weight Management Program scored higher than obese ones in the general population in Reward Dependence and Cooperativeness. Patients who scored lower in Novelty seeking were more successful in losing weight after the program of behavioral therapy than patients who scored higher.

The study of Tambelli et al, ${ }^{48}$ evaluated psychological profiles of the obese subjects, and tested the influence of psychopathological risk and impulsivity on body mass index and quality of life. The signs of somatization and psychoticism were predictors of a higher body mass index in men. There was no relation among psychopathological symptoms and the quality of life in men. In women, somatization and attentional impulsivity were predictors for a higher body mass index. There was no connexion between the psychopathological risk and quality of life in women. The regression analysis showed that somatization is a "core" psychopathological symptom in obese patients regardless of their sex, which is a potential predictor for a higher body mass index.

There is a connection between internalizing/externalizing behavior in children and overweight. Ceniglia et al, ${ }^{49}$ study employed a growth curve modeling over three age 
points $(2,5$, and 8 years) in community sample to: (1) show body mass index trajectories in two subgroups of children (normal weight and overweight) aged from two to eight years; (2) show the developmental trajectories of children's depressive and aggressive symptoms. Whereas overweight girls' body mass index was constantly high, boys' enlarged at the age of five and eight. The rates for aggressivity at two years of age were the same in both groups, but a substantial difference arose from two years to five years in both samples, in different directions. Depressive symptoms had dissimilar initial points in two groups; the children with normal weight had lower scores than overweight. Overweight girls displayed lower depressive rates than overweight boys at two years age, but they exceeded boys before the age of five, and presented more maladaptive indicators at the age of eight.

\section{Quality of life and body weight}

Body mass index contributes to the prediction of decreased quality of life. This relation has been confirmed repetitively for low physical movement. ${ }^{49-55}$ This association can be bidirectional. In a large study in young Swiss men decreased quality of life is associated with deviations from normal weight in both directions. ${ }^{56}$ Both overweight and obese men claimed they dropped the physical quality of life in comparison to normal weight persons, while underweight recruits suffered from the compromised mental quality of life. Unexpectedly, obese men stated they enhanced subjective quality of life.

\section{Study aims and hypotheses}

This presentation aims to look at the connection between chosen psychological and anthropometric parameters. In this article, we can see the first part results of the large project, the protocol of which we presented in our previous report. "Psychological, psychophysiological, and anthropometric correlates of CVDs". ${ }^{24}$ In previous pilot study, we compared the psychological, psychophysiological, and anthropometric factors connected with life events, depresivity, and quality of life of the healthy participants and patients with cardiovascular problems. ${ }^{25}$ In healthy controls, a higher amount of life events significantly negatively correlated with High-frequency total power, a possible marker of parasympathetic tone, and the level of depression correlates with overweight. In patients with cardiovascular problems, a score of life events is not linked with the cardiovascular of anthropometric factors. In the present study, we focused on personality factors measured by Temperament and Character
Inventory-Revised (TCI-R) influencing anthropometric factors (Waist/height ratio and Percentage of the visceral fat) in healthy adults. The primary hypotheses of the present study, built from the information as mentioned above, were as follows: The anthropological parameters (Waist/height ratio and Percentage of the visceral fat) are influenced by:

1. Stress-induced life events in the last two years

2. Novelty-seeking

3. Harm-avoidance

4. Reward-dependence

5. Persistence

6. Self-directedness

7. Cooperativeness

8. Negative affectivity

9. Quality of life

\section{Method}

Cross-sectional study will collect the data for the evaluation of the relationship between psychological factors and anthropometric parameters.

\section{Participants and study setting}

The study target was the recruitment of about two hundreds of healthy persons with no medication influencing the autonomic nervous system or body weight in the age in the range 18-65 years with the same number of participants in every decade.

\section{Study settings}

The probands were assessed in standard settings from 8.00 a.m. to 1 p.m. in the cardiology outpatient clinic. The measurements included an administration of questionnaires, the physical examination, the measurement of the blood pressure, and anthropological analyses. During the first 15 mins, participants were informed about the procedure and sign up the informed consent. This interval was also used for the participant's adaptation for the setting and calm down. Subsequently, the cardiological, psychological, psychophysiological, and anthropometric measurements were delivered. ${ }^{24}$

\section{Measurements}

The following questionnaires have been used in the crosssectional study:

(a) Social Readjustment Rating Scale (SRRS) - the life events questionnaire has 43 items, most of which are taken from Holmes and Rahe's Schedule of 
Recent Events. ${ }^{57}$ At a 2-year assessment, the occurrence of stress-induced adverse life events was evaluated.

(b) Temperament and Character Inventory-Revised (TCI-R) - The revised version of the Inventory of Temperament and Character consists of 240 items. $^{58}$ The questionnaire evaluates four temperamental and three character personality traits. Features of temperament include Novelty Seeking (NS), Harm Avoidance (HA), Reward Dependence (RD), and Persistence (PS). Characteristic features include Self-directedness (SD), Cooperativeness (CO), and Self-transcendence (ST) ${ }^{59}$ The questionnaire is composed of a series of true/false questions about the test taker's likes and dislikes, emotional reactions, interests, attitudes, goals, and values, which is then scored to assess the different dimensions of personality (Example of the item of eg Cooperativeness: "People involved with me have to learn how to do things my way"). Each of the seven aspects is uniquely heritable and associated with specific neurotransmitter genes and regional brain activity. ${ }^{60}$ Czech percentile standards were created by Preiss and Klose. ${ }^{61}$ Psychometric properties of the Slovak version were evaluated by Heretik and Hajduk. ${ }^{62}$ Temperaments are traits of emotional reactions and are constant through time, while characters are traits of psychological self-governance and are developed and matured during life.

(c) Type-D Scale (DS-14). ${ }^{63}$ D-type personality is defined as an increased tendency to experience negative emotions (negative affectivity) in connection to non-express feelings (social inhibition). Type-D scale consists of the NA (Negative affectivity) and SI (Social inhibition) subscales. Each subscale contains seven items. Negative affectivity is connected with the tendency to experience negative emotions like anxiety, anger, hostility, irritability, and dysphoria (example of the item: "I often feel unhappy"). Social inhibition refers to the difficulties in emotion expression and discomfort in social situations. ${ }^{64}$ (example of the item: "I often feel inhibited in social interactions"). If a person rates $\geq 10$ on both domains, the person is classified as having a Type-D-personality. A score $<10$ designates the nonappearance of Type-D-personality. ${ }^{63}$ Type $\mathrm{D}$ is considered to be relatively stable personal characteristic. ${ }^{65}$ Slovakian adaptation of inventory was prepared by Durka and Ruch with excellent psychometric properties. ${ }^{66}$

(d) EuroQol Group 5-Dimension Self-Report Questionnaire (EQ-5D) - is used for the assessment of the quality of life. The questionnaire contains five broad domains: mobility, self-care, usual activities, pain/discomfort, and anxiety/depression. ${ }^{67,68}$ (Example of the item: USUAL ACTIVITIES (eg, work, study, housework, family or leisure activities): I have no problems doing my usual activities $\square$; I have slight problems doing my usual activities $\square$; I have moderate problems doing my usual activities $\square$; I have severe problems doing my usual activities $\square$; I am unable to do my usual activities $\square$ ). The additional measure is the EQ-5D visual analog scale (VAS). EQ-5D is extensively used in various countries in different clinical areas with good validity and reliability. ${ }^{68-71}$

(e) Demographic questionnaire (DD) checked the necessary information such as proband age, marital and partnership status, employment status, education, pension status, subjective overall psychological well-being, and average physical activity during a week.

Basic anthropometric parameters were measured: weight, height, waist circumference, Waist/Height ratio, blood pressure, heart rate at rest. The probands were measured on the standard conditions in the outpatient cardiology clinic from 8 a.m. to 1 p.m. in fasting state. During the first 15 mins, participants were informed about the procedure and sign up the informed consent. This interval was also used for the participant's adaptation for the setting and calm down. Subsequently, the cardiological, psychological, psychophysiological, and anthropometric measurements were delivered. The measurements included an administration of questionnaires by clinical psychologists (co-authors of the article: AK, MK, MZ, MC); the physical examination, and anthropological measurements done by physician with specialization on internal medicine (coauthor: IM). A trained research nurse was responsible for weight, height, blood pressure, and heart rate at the rest measurements from all subjects. All subjects were weighed in light clothing; jackets, coats, and shoes were removed. The weighing measures were calibrated monthly. WHR (Waist-to-height ratio) is defined as the waist perimeter divided by height, both measured in the same units. Body composition measurements were taken using 
bioimpedance body composition analyses frequency segmental bioimpedance (InBody 230 produced by Biospace Co., Ltd.). For the purpose of the research, WHR and Percentage of the visceral fat were selected.

\section{Statistics}

Statistics were calculated by using statistical software SPSS 24.0 for Windows. Demographic, anthropomorphic, and psychological data were analyzed using column statistics. The Shapiro-Wilk W test determined the normal distribution of the demographic and clinical variables. Partial correlations analyzed relationships between outcome factors and other factor correlations. Differences between scores or measures were computed by unpaired $t$-tests or Mann-Whitney tests in dichotomous subgroups of data. To evaluate the correlation coefficient, the Cohen model of the correlation force developed for psychological testing (1988) was used, with a very weak correlation (0.00-0.09), weak correlation (0.09-0.29), a moderate relationship (0.30-0.49), and a strong relationship $(0.50$ $1.00)$. For reduction of the multicollinearity, the regression analyses were made. Differences were reflected as significant when $p$-values were less than 0.05 .

\section{Ethical issues}

The investigation was performed in agreement with the latest version of the Helsinki Declaration and the Guideline for Good Clinical Practice. ${ }^{72}$ The local ethical committee of the Faculty of Social Science and Health Care, Constantine the Philosopher University in Nitra approved the study (date: 2.12.2016, no: 2016/12). Written informed consent was picked up from participants after the procedures were fully explained.

\section{Results}

\section{Sample description}

This investigation was a cross-sectional study of the Slovak general adult population. Two hundred twenty-seven probands take part in the study. The average age was 39.6 \pm 12.9 years. There were more women $(n=137 ; 60.4 \%)$ than men $(n=90 ; 39.6 \%)$ and higher amount of secondary educated persons $(54.6 \%)$. Most of the contributors lived with a spouse $(60.4 \%)$ and were in employment $(80.1 \%)$ or students $(13.7 \%)$. The $41.8 \%$ of contributors had an overweight or obesity $(n=95)$. There were $14.9 \%$ contributors, who were underweight $(n=34)$, and $43.3 \%$ contributors had a normal weight $(n=98)$. The contributor's characteristics are summarised in Table 1.

All primary outcome measures (Waist/Height ratio and Percentage of the visceral fat correlate in both sexes significantly positively with the age (in women: Waist/height ratio $\mathrm{r}=0.41 p<0.001$; Percentage of the visceral fat $\mathrm{r}=0.38$, $p<0.001$; in men: Waist/height ratio $\mathrm{r}=0.43 p<0.001$; Percentage of the visceral fat $\mathrm{r}=0.37, p<0.001$ ).

\section{Psychological factors and anthropometric measurements}

The main concern of the study was to evaluate the relationship between psychological characteristics and anthropometric features. The first step was correlation analysis, the second one regression analysis. All analyses were weighted by age.

\section{Correlation analysis}

To detect relationships between stress-induced adverse life events, personality traits, dissociation, quality of life and anthropometric measures, partial correlation controlling for age was calculated. The age control is needed because both anthropometric features getting worse with the age. The subjects were divided according to the sex because of different anthropometric characteristics (Table 1).

\section{Social Readjustment Rating Scale (SRRS)}

Both in women and in men, the life events in the last two years measured by SRRS do not correlate statistically significantly with used anthropometric measures (Table 2).

Temperament and Character Inventory-Revised (TCl-R) When looking on temperament and character traits in women Novelty-seeking weakly negative correlates with Percentage of the visceral fat. It means that women with higher Novelty-seeking have less percentage of fat in the abdominal part of the body (Table 2). The other temperamental trait Harm-avoidance weakly positively correlates with Waist/height ratio and Percentage of the visceral fat. It means that women with higher tendency to avoidance are more overweight and vice versa. No other personality trait measured by TCI-R (Reward-dependence, Persistence, Selfdirectedness, Cooperativeness, and Self-transcendence) did correlate with any of anthropometric measurements.

Novelty-seeking, Harm-avoidance, Persistence, Selfdirectedness, Cooperativeness, and Self-transcendence did not correlate with any of anthropometric measurements (Table 2). 
Table I Participants' characteristics

\begin{tabular}{|c|c|c|c|c|}
\hline Variables & Whole sample $(n=227)$ & Women $(n=137)$ & Men $(n=90)$ & Difference between sexes: $p$-value \\
\hline Age (years) & $39.57 \pm 12.9$ & $39.47 \pm 11.98$ & $39.72 \pm 14.23$ & ns \\
\hline Height $(\mathrm{cm})$ & $172.54 \pm 8.92$ & $167.35 \pm 5.84$ & $180.52 \pm 6.66$ & $p<0.001$ \\
\hline Waist/height ratio & $0.48 \pm 0.08$ & $0.46 \pm 0.08$ & $0.52 \pm 0.06$ & $p<0.001$ \\
\hline Percentage of visceral fat (\%) & $26.75 \pm 9.28$ & $29.31 \pm 9.12$ & $22.80 \pm 8.12$ & $p<0.001$ \\
\hline SRRS & $122.29 \pm 89.85$ & $|34.49 \pm 99.2|$ & $103.39 \pm 69.45$ & $p<0.01$ \\
\hline \multicolumn{5}{|c|}{ Temperament and Character Inventory-Revised } \\
\hline Novelty-seeking & $99.58 \pm|2.2|$ & $99.99 \pm 12.29$ & $98.94 \pm 12.13$ & ns \\
\hline Harm-avoidance & $88.42 \pm \mid 9.21$ & $91.61 \pm 19.90$ & $83.51 \pm 17.07$ & $P<0.001$ \\
\hline Reward-dependence & $96.88 \pm 12.07$ & $100.02 \pm 11.66$ & $92.05 \pm 11.12$ & $p<0.001$ \\
\hline Persistence & $120.14 \pm 19.36$ & $118.15 \pm 18.00$ & $123.20 \pm 21.04$ & ns \\
\hline Self-Directedness & $139.76 \pm 15.38$ & $139.58 \pm 14.64$ & $140.04 \pm 16.29$ & ns \\
\hline Cooperativeness & $129.52 \pm 15.32$ & $133.34 \pm 14.13$ & $123.65 \pm 15.29$ & $p<0.001$ \\
\hline Self-Transcendence & $72.45 \pm 15.23$ & $74.44 \pm 15.56$ & $69.39 \pm 14.25$ & $p<0.05$ \\
\hline \multicolumn{5}{|l|}{ Type-D Scale } \\
\hline Negative affectivity & $8.92 \pm 5.78$ & $9.12 \pm 5.80$ & $8.59 \pm 5.76$ & ns \\
\hline Social inhibition & $9.60 \pm 5.10$ & $9.42 \pm 5.03$ & $9.87 \pm 5.21$ & ns \\
\hline \multicolumn{5}{|c|}{ EuroQol Group 5-Dimension Self-Report Questionnaire } \\
\hline Total score & $5.56 \pm 0.96$ & $5.63 \pm 1.01$ & $5.45 \pm 0.89$ & ns \\
\hline Visual analog scale & $84.81 \pm 12.39$ & $84.15 \pm 14.00$ & $85.84 \pm 9.37$ & ns \\
\hline Subjective psychological well-being & $81.05 \pm 15.08$ & $79.37 \pm 14.62$ & $83.65 \pm 15.50$ & $p<0.05$ \\
\hline Physical activity (hours per week) & $6.81 \pm 9.61$ & $5.88 \pm 8.96$ & $8.27 \pm 10.44$ & ns \\
\hline
\end{tabular}

Abbreviations: SRRS, the Social Readjustment Rating Scale; ns, not significant.

Table 2 Partial correlations - anthropometric and psychological factors

\begin{tabular}{|l|l|l|l|l|}
\hline \multirow{2}{*}{ Measurement } & \multicolumn{2}{l|}{ Women } & \multicolumn{2}{l|}{ Men } \\
\cline { 2 - 5 } & Waist/height ratio & Percent visceral fat & Waist/height ratio & Percent visceral fat \\
\hline SRRS & 0.11 & -0.01 & -0.04 & -0.07 \\
Novelty seeking & -0.13 & $-0.25^{* *}$ & 0.09 & 0.00 \\
Harm avoidance & $0.21^{*}$ & $0.24^{* *}$ & -0.14 & 0.06 \\
Reward dependence & -0.01 & -0.01 & 0.22 & 0.18 \\
Persistance & 0.01 & -0.05 & 0.10 & 0.04 \\
Self-directedness & -0.18 & -0.14 & -0.12 & -0.03 \\
Cooperativeness & 0.0 .05 & 0.03 & -0.07 & 0.01 \\
Self-transcendence & -0.17 & -0.15 & -0.05 & -0.22 \\
DSI4 Negative affectivity & $0.35^{* * *}$ & $0.32^{* * *}$ & -0.05 & 0.21 \\
DSI4 Social inhibition & 0.13 & $0.18^{*}$ & -0.12 & 0.12 \\
EQ5D total score & $0,22^{*}$ & 0.15 & -0.11 & -0.16 \\
EQ5D visual analog scale & $-0.37^{* * *}$ & $-0.18^{*}$ & 0.02 & -0.04 \\
Physical activity & -0.07 & -0.11 & 0.17 & 0.06 \\
Subjective overall well-being & $-0.20^{*}$ & -0.12 & -0.11 & -0.12 \\
\hline
\end{tabular}

Notes: $p$-values: $* p<0.050$. $* * p<0.010$. *** $p<0.001$

Abbreviations: SRRS, Social Readjustment Rating Scale; EQ5D TOTAL, EuroQol Group 5-Dimension Self-Report Questionnaire-total score; EQ5D SCALE, EuroQol Group 5-Dimension Self-Report Questionnaire - visual analog scale. 


\section{Type-D Scale (DS- I4)}

Both components of D-type personality correlate with anthropometric measures in women. Negative affectivity (NA) moderately positively correlates with Waist/height ratio and Percentage of the visceral fat. It means that women with higher tendency to experience negative emotions, like dysphoria, anger, anxiety, or irritability have higher tendency to be overweight and vice versa. Similarly, the factor of D-type personality Social inhibition (SI) weakly positively correlates with Percentage of the visceral fat in women. It means that women with problems with higher expression of emotion, who experienced discomfort in social situations, are slightly more probably overweight.

It looks that there is no relation between negative affectivity and social inhibition and overweigh in men. Component of Dtype personality Negative affectivity does not correlate with any of the anthropometric measures (Table 2). Similarly, component of D-type personality Social inhibition does not correlate with any of anthropometric measures.

\section{EuroQol Group 5-Dimension Self-Report Questionnaire (EQ-5D)}

Total score of EQ5D weakly positively correlated with Waist/height ratio in women. EQ5D3L SCALE moderately negatively correlates with Waist/height ratio, and weakly negatively with Percentage of the visceral fat in women (Table 2).

In men, total score EQ5D TOTAL did not correlate with any of anthropometric measures and also EQ5D SCALE did not correlate with any of anthropometric measures (Table 2).

\section{Physical activity}

In women, the subjective declared hours of weekly physical activity do not correlate with any of the anthropometric measures (Table 2).
In men, the subjective declared hours of weekly physical activity do not correlate with any of the anthropometric measures (Table 2).

\section{Subjective overall well-being}

In women, the overall subjective well-being statistically significantly weakly negatively correlates with Waist/ height ratio (Table 2).

In men, overall subjective well-being does not correlate with any of the anthropometric measures (Table 2).

\section{Regression analysis}

\section{Regression analysis - waist/height ratio}

To detect the most significant variables connected with Waist/height ratio, a multiple regression analysis (backward stepwise regression) weighted by age was calculated. As a dependent variable, the Waist/height ratio was used. Independent variables were SRRS, Novelty-seeking, Harmavoidance, Reward-dependence, Persistence, Self-directedness, Cooperativeness, Self-transcendence, DS-14 NA, DS14 SI, EQ5D TOTAL, EQ5D SCALE, declared physical activity, and subjective overall psychical well-being. In women, during ten steps of the backward stepwise regression, two factors sustained with statistical significance Harm-avoidance and EQ5D SCALE - both of them explain $19.85 \%$ of Waist/height ratio (Table 3).

In men, during eleven steps two factors remained significant - there are Reward-dependence, Cooperativeness, explaining $8.0 \%$ of Waist/height ratio (Table 4 ).

\section{Regression analysis - percentage of the visceral fat}

Backward stepwise regression was performed to identify the most important factors linked to the Percentage of the visceral fat as the dependent variable. Independent variables were SRRS, Novelty-seeking, Harm-avoidance, Reward-dependence, Persistence, Self-directedness, Cooperativeness,

Table 3 Multiple regression analysis of the Waist/height ratio as the dependent variable

\begin{tabular}{|c|c|c|c|c|c|c|c|}
\hline Gender & Model & Regressors & B & SE & $\boldsymbol{\beta}$ & $\mathbf{t}$ & p-Value \\
\hline \multirow[t]{4}{*}{ Women } & \multirow[t]{4}{*}{10} & Harm-avoidance & 0.00 & 0.00 & 0.36 & 3.21 & 0.002 \\
\hline & & Persistence & 0.00 & 0.00 & 0.21 & 1.91 & 0.059 \\
\hline & & EQ-5D visual analogue scale & -0.00 & 0.00 & -0.35 & -3.96 & 0.001 \\
\hline & & \multicolumn{6}{|c|}{ ANOVA: $F=9.548 \mathrm{df}=104 ; p<0.001$ Adjusted $r$ squared $=0.198$} \\
\hline \multirow[t]{3}{*}{ Men } & \multirow[t]{3}{*}{11} & Reward dependence & 0.00 & 0.00 & 0.40 & 2.69 & 0.009 \\
\hline & & Cooperativeness & -0.00 & 0.00 & -0.32 & -2.18 & 0.033 \\
\hline & & \multicolumn{6}{|c|}{ ANOVA: $F=3.863 \mathrm{df}=66 ; p<0.01$ Adjusted $r$ squared $=0.08$} \\
\hline
\end{tabular}

Abbreviation: SE, standard error. 
Table 4 Multiple regression analysis of the Percentage of the visceral fat as the dependent variable

\begin{tabular}{|c|c|c|c|c|c|c|c|}
\hline Sex & Model & Regressors & B & SE & $\boldsymbol{\beta}$ & $\mathbf{t}$ & p-Value \\
\hline \multirow[t]{5}{*}{ Women } & \multirow[t]{5}{*}{9} & SRRS & -0.02 & 0.01 & -0.20 & -20.19 & 0.031 \\
\hline & & Novelty seeking & -0.20 & 0.08 & -0.23 & -20.60 & 0.011 \\
\hline & & DSI4 Negative affectivity & 0.37 & 0.15 & 0.23 & 20.45 & 0.016 \\
\hline & & EQ-5D visual analogue scale & -0.23 & 0.08 & -0.28 & -30.05 & 0.003 \\
\hline & & \multicolumn{6}{|c|}{ ANOVA: $\mathrm{F}=7.685 \mathrm{df}=103 ; p<0.001$ Adjusted $r$ squared $=0.206$} \\
\hline \multirow[t]{3}{*}{ Men } & \multirow[t]{3}{*}{11} & Self-transcendence & -0.14 & 0.07 & -0.23 & -10.97 & 0.054 \\
\hline & & EQ-5D visual analogue scale & -0.21 & 0.10 & -0.24 & -10.98 & 0.052 \\
\hline & & \multicolumn{6}{|c|}{ ANOVA: $F=3.973 d f=65 ; p<0.05$ Adjusted $r$ squared $=0.084$} \\
\hline
\end{tabular}

Abbreviations: SE, standard error; SRRS, Social Readjustment Rating Scale.

Self-transcendence, DS-14 NA, DS-14 SI, EQ5D TOTAL, EQ5D SCALE, declared physical activity, and subjective overall psychical well-being. The most influential factors connected with the Percentage of the visceral fat are SRRS, Novelty-seeking, DS-14 NA, and EQ5D scale in women (explaining $21 \%$ of Percentage of the visceral fat).

\section{Discussion}

The primary objective was to establish a connection between psychosocial characteristics and body anthropometric parameters of body proportions known as a risk factor for CVDs. Built on the background facts described in the part of Introduction, several hypotheses were designated.

In the ten hypotheses, there was expected that there is a relationship between body anthropological parameters and:

\section{Stressful life events in the last two years}

According to the correlation analysis, there are no correlations between life events in the previous two years and any of used body anthropometric measures both in women and in men. Nevertheless, in backward regression analysis, which take into account interrelation between all entering psychological factors, the score of life events has a statistically significant link to Percentage of the Percentage of visceral fat in women, but not in men. This confirms the relationship between life events and particular anthropometric measures. In our previous study, Slepecky et $\mathrm{al}^{24}$ showed that life events in the last two years are connected with overweight, but the population was different (half of the probands had treated CVDs). It is difficult to say if the increased percentage of visceral fat is the consequence of the higher amount of the life events in last two years or the direction is opposite, because of the cross-sectional design of the study. Only a longitudinal study might answer this question.

\section{Novelty seeking}

Novelty seeking in correlation analysis weakly negatively correlates with Percentage of the visceral fat in women, but not in men. It means that lower Novelty-seeking scores connect with higher percentage of abdominal fat in women. Novelty seeking is the personality trait combined with exploratory activity in reaction to new stimulus, impulsivity, spontaneous decision-making, and extravagance. ${ }^{73}$ It has been recognized to be mostly inborn. ${ }^{74}$ Novelty seeking decreases with time. ${ }^{75}$ Several studies described that higher scores of Novelty seeking are connected with overeating in patients with eating disorders, ${ }^{43-48,76,77}$ and obese individuals scored higher in Novelty seeking. ${ }^{34}$ The results of our study suggest the opposite direction. We had no patients with the eating disorder or with BDI lower than 17.

\section{Harm avoidance}

In correlation analysis, Harm avoidance (HA) weakly positively correlates with Waist/height ratio and Percentage of the visceral fat in women but not in men. Harm avoidance is a personality trait characterized by pessimism; fear of uncertainty, excessive worrying; shyness; and being doubtful, fearful, and easily fatigued. In several investigations, a higher Harm avoidance correlated with overweight or obesity. ${ }^{50,78-81}$ In the regression analysis, there is a significant link between Harm avoidance and Waist/height ratio in women.

\section{Reward dependence}

In the correlation analysis, Reward dependence does not correlate with any of the body anthropometric measures in women or in men. The regression analysis confirms these results in women. In men, in regression analysis, there is a significant relation between Reward dependence and 
Waist/height ratio and Percentage of the visceral fat. It means that men with higher Reward dependence are more prone to be overweight. The "sensitivity to reward", was found as a risk factor in relative to control of weight. ${ }^{39,82,83}$ Reward dependence is considered as an inclination to react remarkably to the signals of reward, predominantly to verbal keys of social agreement, social care, and sentiment. ${ }^{84}$ Cloninger suggested that a single monoamine neurotransmitter system influences Reward dependence: the noradrenergic system and Reward dependence are correlated with low basal noradrenergic activity. ${ }^{84-86}$ Persons in high scores of Reward dependence are ambitious, pleasant, sentimental, warm, and sociable; nevertheless, these individuals are marketable socially dependent. ${ }^{87}$ Reward dependence is viewed as a moderately heritable feature which is relatively constant during the life. Individuals low in reward dependence and high in norepinephrine levels are then hypothesized to be typically independent, non-conformist, practical, toughminded, cynical, unwilling to share their intimate feelings with others, socially detached, irresolute, insensitive to social cues and pressures, and content to be alone. They are also minimally motivated to please others and act for immediate gratification. The attrition in weight management programs is linked to the neural mechanisms associated with rewardseeking. ${ }^{88,89}$ A poor reward-related decision-making is associated with weight cycling. ${ }^{90}$

\section{Self-directedness}

In both sexes, Self-directedness does not correlate with Waist/height ratio or Percentage of visceral fat in the correlation analysis. According to the multiple regression analysis, there is no significant relation between Self-directedness anthropometric measures in both sexes. There are several opposite results in the literature in specific groups of patients. Participants with food addiction presented less Self-directedness that participants without food addiction among patients with severe obesity awaiting bariatric surgery. ${ }^{91}$ In Sarısoy et al, ${ }^{79}$ study low self-directedness may be an important personality characteristic in a process leading to morbid obesity. Personality traits of obese individuals included significantly lower self-directedness also in another study. ${ }^{81}$ In the survey of Garcia et al, ${ }^{92}$ obese and overweight patients scored in Self-directedness even lower.

\section{D-type personality}

Components of D-type personality include negative affectivity (NA) and social inhibition (SI). Negative affectivity denotes the inclination to experience distress, unrelatedly on place or time. ${ }^{93}$ Social inhibition refers to the suppression of negative emotions in social communications. ${ }^{94}$ In the present study, negative affectivity moderately positively correlates with both used anthropometric measures (Waist/height ratio, Percentage of visceral fat) in women, but not in men. It means that women with higher negative affectivity are more overweight or obese. In women, also the Social inhibition subscale is weakly positively related to Percentage of visceral fat. International studies have recently associated D-type personality with CVDs including hypertension, coronary artery disease, and heart failure. ${ }^{95,96}$ The significant association between Negative affectivity and Percentage of the visceral fat was confirmed also in multiple regression analyses in women.

\section{Quality of life}

In women EQ5D TOTAL positively correlated with Waist/ height ratio. It means that women with overweight have a lower quality of life. There is also confirm in EQ5D VAS. For Waist/height ration and Percentage of visceral fat. The link between EQSD VAS and Waist/high ratio and Percentage of the visceral fat was confirmed also in regression analysis.

In men, there is no correlation between the quality of life and body anthropomorphic measurement. The same result was confirmed in regression analysis.

\section{Limitations of the study}

The current study has several shortcomings. The main limitation is the number of participants. The relatively small sample size, mostly in men, is a limitation for the used statistical approaches, mainly regression analysis.

Secondarily, participants completed the self-report questionnaires, which may be influenced by the present state of the person, willingness to collaborate, and the capability of self-reflection. The questionnaires were relatively extensive so that participants may have been drained. Also, few probands did not fill in the forms fully, so they had to be excluded from some examines.

Another limit of the investigation is the project method because a cross-sectional exploration could not explain the causatives of the correlations, which can be manifold. Identified connections may be difficult to interpret. One should be cautious while trying to indicate causal mechanisms based on the data collected at one point in time. To decrease this, limitation regression analysis was done to omitted collinear factors. Nevertheless, such statistical evaluation with a quite small quantity of patients has the limits. 
However, the most outcomes are by the results of other researches in an associated area. Some results, however, are exclusive and comparison with the results of other studies was not possible.

Despite these limitations, the psychosocial factors prove to be important aspects connecting with body anthropometric factors connecting with body weight.

\section{Implications for further research}

Furthermore, the TCI and Type-D Scale were able to recognize specific personality traits that were related to a quick and continued reaction to cognitive behavioral therapy for bulimia and obesity. ${ }^{77}$ The future investigation should continue with the effort to find the pathways of the psychological factors impact on overweight and obesity, their prevention and therapy.

\section{Conclusion}

Outcomes propose some promising tools by which personality factors may influence overweight and obesity. Monitoring these factors could be a significant contribution to preventive obesitology. The results have a substantial impact on thinking about the detection of psychological factors which are in a relationship with a higher risk of overweight and consequently on the CVDs and could help with the plan the psychoeducational and lifestyle changes for the individuals who experience a high probability to develop overweight and obesity. Studies on the outcome benefits of cognitive behavioral therapy, reasonable dietology, and exercise training, have been convincing.

The main findings of the present study were two: first, there is a relationship between body anthropometric parameters connecting with overweight and particular personality factors, like Novelty seeking, Harm Avoidance, Reward Dependence, and Negative affectivity in the female. Secondly, the personality traits correlated significantly also with the quality of life, which correlates with anthropometric parameters. Clinical implications include the importance of interventions against overweight and obesity.

\section{Acknowledgments}

This paper was supported by the research grant VEGA no. APVV-15-0502 Psychological, psychophysiological and anthropometric correlates of cardiovascular diseases.

\section{Disclosure}

The authors report no conflicts of interest in this work.

\section{References}

1. Alboni P, Alboni M. Psychosocial factors as predictors of atherosclerosis and cardiovascular events: contribution from animal models. G Ital Cardiol (Rome). 2006;7(11):747-753.

2. Franklin BA. Impact of psychosocial risk factors on the heart: changing paradigms and perceptions. Phys Sportsmed. 2009;37(3):35-37. doi:10.3810/psm.2009.10.1727

3. Fabre B, Grosman H, Mazza O, et al. Relationship between cortisol, life events and metabolic syndrome in men. Stress. 2013;16(1):1623. doi: $10.3109 / 10253890.2012 .676112$

4. Chen Z, Yang G, Zhou M, et al. Body mass index and mortality from ischaemic heart disease in a lean population: a 10-year prospective study of 220.000 adult men. Int J Epidemiol. 2006;35(1):141-150. doi:10.1093/ije/dyi215

5. Guh DP, Zhang W, Bansback N, Amarsi Z, Birmingham CL, Anis $\mathrm{AH}$. The incidence of co-morbidities related to obesity and overweight: a systematic review and meta-analysis. BMC Public Health. 2009;9:88. doi:10.1186/1471-2458-9-253

6. Prospective Studies Collaboration. Body-mass index and cause-specific mortality in 900000 adults: collaborative analyses of 57 prospective studies. Lancet. 2009;373(9669):1083-1096. doi:10.1016/ S0140-6736(09)60318-4

7. Alpert MA, Lavie CJ, Agrawal H, Aggarwal KB, Kumar SA. Obesity and heart failure: epidemiology, pathophysiology, clinical manifestations, and management. Transl Res. 2014;164:345-356. doi:10.1016/ j.trs 1.2014 .04 .010

8. Barquera S, Pedroza-Tobías A, Medina C, et al. Global overview of the epidemiology of atherosclerotic cardiovascular disease. Arch Med Res. 2015;46:328-338. doi:10.1016/j.arcmed.2015. 06.006

9. Khazem S, Itani L, Kreidieh D, et al. Reduced lean body mass and cardiometabolic diseases in adult males with overweight and obesity: a pilot study. Int $J$ Environ Res Public Health. 2018;15(12):pii: E2754. doi:10.3390/ijerph15061188

10. González-Muniesa P, Mártinez-González MA, Hu FB, et al. Obesity. Nat Rev Dis Primers. 2017;3:17034. doi:10.1038/nrdp.2017.34

11. Yen YC, Huang CK, Tai CM. Psychiatric aspects of bariatric surgery. Curr Opin Psychiatry. 2014;27:374-379. doi:10.1097/ YCO.0000000000000085

12. WHO Expert Consultation. Appropriate body-mass index for Asian populations and its implications for policy and intervention strategies. Lancet. 2004;363:157-163. doi:10.1016/S0140-6736(03)15268-3

13. Holley TJ, Collins CE, Morgan PJ, Callister R, Hutchesson MJ. Weight expectations, motivations for weight change and perceived factors influencing weight management in young Australian women: a cross-sectional study. Public Health Nutr. 2016;19:275-286. doi:10.1017/S1368980015003110

14. Ghaddar F, Salameh P, Saleh N, et al. Noncardiac Lebanese hospitalized adult patients' awareness of their coronary artery disease risk factors. Vasc Health Risk Manag. 2018;14:371-382. doi:10.2147/ VHRM.S176167

15. Schneider HJ, Friedrich N, Klotsche J, Pieper L, Nauck M, John U. The predictive value of different measures of obesity for incident cardiovascular events and mortality. $J$ Clin Endocrinol Metab. 2010;95(4):1777-1785. doi:10.1210/jc.2009-1584

16. Ohlson LO, Larsson B, Svärdsudd K, et al. The influence of body fat distribution on the incidence of diabetes mellitus: 13.5 years of follow-up of the participants in the study of men born in 1913 . Diabetes. 1985;34:1055-1058. doi:10.2337/diab.34.10.1055

17. Després JP. Health consequences of visceral obesity. Ann Med. 2001;33(8):534-541.

18. Suk SH, Sacco RL, Boden-Albala B, et al. Abdominal obesity and risk of ischemic stroke: the Northern Manhattan Stroke Study. Stroke. 2003;34(7):1586-1592. doi:10.1161/01.STR.0000075294. 98582.2F 
19. Canoy D. Distribution of body fat and risk of coronary heart disease in men and women. Curr Opin Cardiol. 2008;23(6):591-598. doi:10.1097/HCO.0b013e328313133a

20. Ashwell M. Obesity risk: importance of the waist-to-height ratio. Nurs Stand. 2009;23:49-54. doi:10.7748/ns2009.06.23.41.49.c7050

21. Han E, Lee YH, Lee BW, Kang ES, Lee IK, Cha BS. Anatomic fat depots and cardiovascular risk: a focus on the leg fat using nationwide surveys (KNHANES 2008-2011). Cardiovasc Diabetol. 2017;16:54. doi:10.1186/s12933-017-0624-5

22. Gruzdeva O, Borodkina D, Uchasova E, Dyleva Y, Barbarash O. Localization of fat depots and cardiovascular risk. Lipids Health Dis. 2018;17(1):218. doi:10.1186/s12944-018-0856-8

23. Wimmelmann CL, Lund R, Christensen U, Osler M, Mortensen EL. Associations between obesity and mental distress in late midlife: results from a large Danish community sample. BMC Obes. 2016;3:54. doi:10.1186/s40608-016-0137-x

24. Slepecky M, Kotianova A, Prasko J, et al. Coping, schemas, and cardiovascular risks - study protocol. Neuropsychiatr Dis Treat. 2017;13:2599-2605. doi:10.2147/NDT.S148837

25. Slepecky M, Kotianova A, Prasko J, et al. Which psychological, psychophysiological, and anthropometric factors are connected with life events, depression, and quality of life in patients with cardiovascular disease. Neuropsychiatr Dis Treat. 2017;13:2093-2104. doi:10.2147/NDT.S141811

26. Cotter EW, Kelly NR. Stress-related eating, mindfulness, and obesity. Health Psychol. 2018;37(6):516-525. doi:10.1037/hea0000614

27. Ozier AD, Kendrick OW, Leeper JD, Knol LL, Perko M, Burnham J. Overweight and obesity are associated with emotion- and stressrelated eating as measured by the eating and appraisal due to emotions and stress questionnaire. J Am Diet Assoc. 2008;108(1):49-56. doi:10.1016/j.jada.2007.10.011

28. Surkan PJ, Sakyi KS, Hu A, et al. Impact of stressful life events on central adiposity in the Pelotas Birth Cohort. Rev Saude Publica. 2018;52:61. doi:10.11606/S1518-8787.2018052000161

29. Björntorp P. Do stress reactions cause abdominal obesity and comorbidities? Obes Rev. 2001;2(2):73-86.

30. Charmandari E, Tsigos C, Chrousos G. Endocrinology of the stress response. Annu Rev Physiol. 2005;67:259-284. doi:10.1146/annurev. physiol.67.040403.120816

31. Torres SJ, Nowson CA. Relationship between stress, eating behavior, and obesity. Nutrition. 2007;23(11-12):887-894. doi:10.1016/j. nut.2007.08.008

32. de Vriendt T, Moreno LA, De Henauw S. Chronic stress and obesity in adolescents: scientific evidence and methodological issues for epidemiological research. Nutr Metab Cardiovasc Dis. 2009;19 (7):511-519. doi:10.1016/j.numecd.2009.02.009

33. Sullivan S, Cloninger CR, Przybeck TR, Klein S. Personality characteristics in obesity and relationship with successful weight loss. Int J Obes (Lond). 2007;31(4):669-674. doi:10.1038/sj.ijo.0803464

34. van Den Bree MBM, Przybeck TR, Cloninger CR. Diet and personality: associations in a population-based sample. Appetite. 2006;46:177-188. doi:10.1016/j.appet.2005.12.004

35. Heaven PC, Mulligan K, Merrilees R, Woods T, Fairooz Y. Neuroticism and conscientiousness as predictors of emotional, external, and restrained eating behaviors. Int J Eat Disord. 2001;30 (2):161-166.

36. Provencher V, Bégin C, Gagnon-Girouard MP, Tremblay A, Boivin $\mathrm{S}$, Lemieux S. Personality traits in overweight and obese women: associations with BMI and eating behaviors. Eat Behav. 2008;9 (3):294-302. doi:10.1016/j.eatbeh.2007.10.004

37. Gerlach G, Herpertz S, Loeber S. Personality traits and obesity: a systematic review. Obes Rev. 2015;16(1):32-63. doi:10.1111/obr.12235

38. Ellickson-Larew S, Naragon-Gainey K, Watson D. Pathological eating behaviors, BMI, and facet-level traits: the roles of conscientiousness, neuroticism, and impulsivity. Eat Behav. 2013;14(4):428-431. doi:10.1016/j.eatbeh.2013.06.015
39. Wimmelmann CL, Lund R, Flensborg-Madsen T, Christensen U, Osler M, Lykke Mortensen E. Associations of personality with body mass index and obesity in a large late midlife community sample. Obes Facts. 2018;11(2):129-143. doi:10.1159/000487888

40. Cloninger CR, Svrakic DM, Przybeck TR. A psychobiological model of temperament and character. Arch Gen Psychiatry. 1993;50:975-999.

41. Cloninger CR, Przybeck TR, Svrakic DM, Wetzel RD. The Temperament and Character Inventory (TCI): $A$ Guide to Its Development and Use. St Louis, MO: Center for Psychobiology of Personality, Washington University; 1994.

42. Svrakic DM, Whitehead C, Przybeck TR, Cloninger R. Differential diagnosis of personality disorders by the seven-factor model of temperament and character. Arch Gen Psychiatry. 1993;50:991-999.

43. Brewerton TD, Hand LD, Bishop ER Jr. The tridimensional personality questionnaire in eating disorder patients. Int $J$ Eat Disord. 1993;14:213-218. doi:10.1002/(ISSN)1098-108X

44. Waller DA, Gullion CM, Petty F, Hardy BW, Murdock MV, Rush AJ. Tridimensional personality questionnaire and serotonin in bulimia nervosa. Psychiatry Res. 1993;48:9-15. doi:10.1016/0165-1781(93) 90108-S

45. Kleifield EI, Sunday S, Hurt S, Halmi KA. The Tridimensional Personality Questionnaire: an exploration of personality traits in eating disorders. J Psychiatr Res. 1994;28:413-423. doi:10.1016/ 0022-3956(94)90001-9

46. Bulik CM, Sullivan PF, Weltzin TE, Kaye WH. Temperament in eating disorders. Int J Eat Disord. 1995;17:251-261. doi:10.1002/ (ISSN)1098-108X

47. Fassino S, Daga GA, Piero A, Leombruni P, Rovera GG. Anger and personality in eating disorders. J Psychosomat Res. 2001;51:757764. doi:10.1016/S0022-3999(01)00280-X

48. Tambelli R, Cerniglia L, Cimino S, et al. An exploratory study on the influence of psychopathological risk and impulsivity on BMI and perceived quality of life in obese patients. Nutrients. 2017;9(5):pii: E431. doi:10.3390/nu9050431

49. Cerniglia L, Cimino S, Erriu M, Jezek S, Almenara CA, Tambelli R. Trajectories of aggressive and depressive symptoms in male and female overweight children: do they share a common path or do they follow different routes? PLoS One. 2018;13(1):e0190731. doi:10.1371/journal.pone.0190731

50. Fassino S, Leombruni P, Piero A, et al. Temperament and character in obese women with and without binge eating disorder. Compr Psychiatry. 2002;43:431-437. doi:10.1053/comp.2002.35906

51. Ford ES, Moriarty DG, Zack MM, Mokdad AH. Chapman DP selfreported body mass index and health-related quality of life: findings from the behavioral risk factor surveillance system. Obes Res. 2001;9 (1):21-31. doi:10.1038/oby.2001.4

52. Larsson U, Karlsson J, Sullivan M. Impact of overweight and obesity on health-related quality of life - a Swedish population study. Int $J$ Obes Relat Metab Disord. 2002;26(3):417-424. doi:10.1038/sj. ijo.0801919

53. Hassan MK, Joshi AV, Madhavan SS, Amonkar MM. Obesity and health-related quality of life: a cross-sectional analysis of the US population. Inter J Obes Relat Metab Disord. 2003;27(10):12271232. doi: $10.1038 /$ sj.ijo.0802396

54. Heath GW, Brown DW. Recommended levels of physical activity and health-related quality of life among overweight and obese adults in the United States, 2005. J Phy Act Health. 2009;6(4):403-411. doi:10.1123/jpah.6.4.403

55. Soltoft F, Hammer M, Kragh N. The association of body mass index and health-related quality of life in the general population: data from the 2003 Health Survey of England. Qual Life Res. 2009;18 (10):1293-1299. doi:10.1007/s11136-009-9478-y

56. Herman KM, Hopman WM, Vandenkerkhof EG, Rosenberg MW. Physical activity, body mass index, and health-related quality of life in Canadian adults. Med Sci Sports Exerc. 2012;44(4):625-636. doi:10.1249/MSS.0b013e31823a90ae 
57. Holmes TH, Rahe RH. The social readjustment rating scale. $J$ Psychosom Res. 1967;11(2):213-218.

58. Farmer RF, Goldberg LR. A psychometric evaluation of the revised Temperament and Character Inventory (TCI-R) and the TCI-14. Psychol Assess. 2008;20(3):281. doi:10.1037/a0012934

59. Gillespie NA, Cloninger CR, Heath AC, Martin NG. The genetic and environmental relationship between Cloninger's dimensions of temperament and character. Pers Individ Dif. 2003;35:1931-1946. doi:10.1016/S0191-8869(03)00042-4

60. Cloninger CR. Biology of personality dimensions. Curr Opin Psychiatry. 2000;13:611-616. doi:10.1097/00001504-200011000-00024

61. Preiss M, Klose J. Diagnostika poruch osobnosti pomocí teorie C. R. Cloningera. [Diagnosis of personality disorders by C.R. Cloninger theory. In Czech]. Psychiatrie. 2001;5:226-231.

62. Heretik A, Hajduk M. Psychometric properties of the Slovak version of the Temperament and Character Inventory (TCI-R) - a preliminary analysis. Annales Psychologici. 2014;1(15):5-11.

63. Denollet J. Standard assessment of negative affectivity, social inhibition, and Type D personality. Psychosom Med. 2005;67(1):89-97. doi:10.1097/01.psy.0000149256.81953.49

64. Denollet J. Personality and coronary heart disease: the type-D scale16 (DS14). Ann Behav Med. 1998;20(3):209-215. doi:10.1007/ BF02884962

65. Denollet J, Schiffer AA, Spek V. A general propensity to psychological distress affects cardiovascular outcomes: evidence from research on the $\mathrm{T}$ (distressed) personality profile. Circ Cardiovasc Qual Outcomes. 2010;3(5):546-557. doi:10.1161/CIRCOUT COMES.109.934406

66. Durka R, Ruch W. Osobnost' typu D v populácii Slovenských univerzitných študentov: psychometrické kvality dotazníka DS14. [Type D personality in Slovak university students: psychometric quality of questionnaire DS14. In Slovak]. Ceskoslovenská Psychológie. 2014;58(1):62-71.

67. Cleemput I. A social preference valuations set for EQ-5D health states in Flanders, Belgium. Eur J Health Econ. 2010;11(2):205213. doi:10.1007/s10198-009-0167-0

68. Alvarado-Bolaños A, Cervantes-Arriaga A, Rodríguez-Violante M, et al. Convergent validation of EQ-5D-5L in patients with Parkinson's disease. J Neurol Sci. 2015;358(1-2):53-57. doi:10.1016/j.jns.2015. 08.010

69. Rabin R, de Charro F. EQ-5D: a measure of health status from the EuroQol Group. Ann Med. 2001;33(5):337-343.

70. Shafie AA, Hassali MA, Liau SY. A cross-sectional validation study of EQ-5D among the Malaysian adult population. Qual Life Res. 2011;20(4):593-600. doi:10.1007/s11136-010-9774-6

71. Berg J, Lindgren P, Mejhert M, Edner M, Dahlström U, Kahan T. Determinants of utility based on the EuroQol five-dimensional questionnaire in patients with chronic heart failure and their change over time: results from the swedish heart failure registry. Value Health. 2015;18(4):439-448. doi:10.1016/j.jval.2015.02.003

72. EMEA. 2002. Available from: http://www.ema.europa.eu/docs/en GB/document_library/Scientific_guideline/2009/09/WC500002874. pdf.Accessed March 20, 2009.

73. Loranger AW, Janca A, Sartorius N. Assessment and Diagnosis of Personality Disorders: The ICD-10 International Personality Disorder Examination (IPDE). Cambridge, U.K.: Cambridge University Press, 1997.

74. Lusher JM, Chandler C, Ball D. Dopamine D4 receptor gene (DRD4) is associated with Novelty-seeking (NS) and substance abuse: the saga continues. Mol Psychiatry. 2001. 6(5):497-499. Available from: http://www.nature.com/mp/journal/v6/n5/full/4000918a.html. doi:10.1038/sj.mp.4000918

75. Gutierrez-Zotes A, Labad J, Martorell L, et al. The revised temperament and character inventory: normative data by sex and age from a Spanish normal randomized sample. Peer J. 2015;3:e1481. doi:10.7717/ peerj. 1481
76. Waller NG, Ross CA. The prevalence and biometric structure of pathological dissociation in the general population: taxometric and behavior genetic findings. J Abnorm Psychol. 1997;106(4):499-510. doi:10.1037/0021-843X.106.4.499

77. Bulik CM, Sullivan PF, Carter FA, McIntosh VV, Joyce PR. Predictors of rapid and sustained response to cognitive-behavioral therapy for bulimia nervosa. Int J Eat Disord. 1999;26:137-144. doi:10.1002/(ISSN)1098-108X

78. López-Pantoja JL, Cabranes JA, Sanchez-Quintero S, et al. Personality profiles between obese and control subjects assessed with five standardized personality scales. Actas Esp Psiquiatr. 2012;40(5):266-274.

79. Sarisoy G, Atmaca A, Ecemiş G, Gümüş K, Pazvantoğlu O. Personality characteristics and body image in obese individuals. Asia Pac Psychiatry. 2014;6(2):191-199. doi:10.1111/appy.12023

80. Dalle Grave R, Calugi S, El Ghoch M. Are personality characteristics as measured by the temperament and character inventory (TCI) associated with obesity treatment outcomes? A systematic review. Curr Obes Rep. 2018;7(1):27-36. doi:10.1007/s13679-018-0294-y

81. Dalle Grave R, Calugi S, Marchesini G, et al., QUOVADIS II Study Group. Personality features of obese women in relation to binge eating and night eating. Psychiatry Res. 2013;207(1-2):86-91. doi:10.1016/j.psychres.2012.09.001

82. Lindroos AK, Lissner L, Mathiassen ME, et al. Dietary intake in relation to restrained eating, disinhibition, and hunger in obese and non-obese Swedish women. Obes Res. 1997;5:175-182. doi:10.1002/ j.1550-8528.1997.tb00290.x

83. Castellanos EH, Charboneau E, Dietrich MS, et al. Obese adults have visual attention bias for food cue images: evidence for altered reward system function. Int $J$ Obes. 2009;33:1063-1073. doi:10.1038/ ijo. 2009.138

84. Cloninger CR. A unified biosocial theory of personality and its role in the development of anxiety states. Psychiatr Dev. 1986;4(3):167-226.

85. Ham BJ, Choi MJ, Lee HJ, Kang RH, Lee MS. Reward-dependence is related to norepinephrine transporter T-182C gene polymorphism in a Korean population. Psychiatr Genet. 2005;15(2):145-147. doi:10.1097/00041444-200506000-00012

86. Yamano E, Isowa T, Nakano $\mathrm{Y}$, et al. Association study between reward-dependence temperament and a polymorphism in the phenylethanolamine N-methyltransferase gene in a Japanese female population. Compr Psychiatry. 2008;49(5):503-507. doi:10.1016/j. comppsych.2008.03.001

87. Pud D, Eisenberg E, Sprecher E, Rogowski Z, Yarnitsky D. The Tridimensional personality theory and pain: harm-avoidance and Reward-dependence traits correlate with pain perception in healthy volunteers. Eur J Pain. 2004;8(1):31-38. doi:10.1016/S1090-3801(03)00065-X

88. De Panfilis C, Torre M, Cero S, et al. Personality and attrition from behavioral weight-loss treatment for obesity. Gen Hosp Psychiatry. 2008;30(6):515-520. doi:10.1016/j.genhosppsych.2008.06.003

89. Koritzky G, Dieterle C, Rice C, Jordan K, Bechara A. Decision-making, sensitivity to reward and attrition in weight management. Obesity (Silver Spring). 2014;22(8):1904-1909. doi:10.1002/oby.20770

90. Brockmeyer T, Simon JJ, Becker A, Friederich HC. Reward-related decision making and long-term weight loss maintenance. Physiol Behav. 2017;181:69-74. doi:10.1016/j.physbeh.2017.09.008

91. Ouellette AS, Rodrigue C, Lemieux S, Tchernof A, Biertho L, Bégin C. An examination of the mechanisms and personality traits underlying food addiction among individuals with severe obesity awaiting bariatric surgery. Eat Weight Disord. 2017;22(4):633-640. doi:10.1007/s40519-017-0440-7

92. Garcia D, Forssell H, Cloninger KM. Aspiring personality: patients waiting for obesity treatment. Psych J. 2018;7(2):103-104. doi:10.1002/pchj.209

93. Pedersen SS, Denollet J, Ong AT, Serruys PW, Erdman RA, van Domburg RT. Impaired health status in Type D patients following PCI in the drug-eluting stent era. Int J Cardiol. 2007;114:358-365. doi:10.1016/j.ijcard.2005.12.018 
94. Watson D, Pennebaker JW. Health complaints, stress, and distress: exploring the central role of negative affectivity. Psychol Rev. 1989;96:234-254.

95. Pedersen SS, van Domburg RT, Theuns DA, Jordaens L, Erdman RA. Type D personality is associated with increased anxiety and depressive symptoms in patients with an implantable cardioverter defibrillator and their partners. Psychosom Med. 2004;66:714-719. doi:10.1097/01.psy.0000132874.52202.21
96. Aquarius AE, Denollet J, Hamming JF, De Vries J. Role of disease status and $\mathrm{T}$ personality in outcomes in patients with peripheral arterial disease. Am J Cardiol. 2005;96:996-1001. doi:10.1016/j. amjcard.2005.05.059

\section{Publish your work in this journal}

Psychology Research and Behavior Management is an international, peer-reviewed, open access journal focusing on the science of psychology and its application in behavior management to develop improved outcomes in the clinical, educational, sports and business arenas. Specific topics covered in the journal include: Neuroscience, memory and decision making; Behavior modification and management; Clinical applications; Business and sports performance management; Social and developmental studies; Animal studies. The manuscript management system is completely online and includes a very quick and fair peer-review system, which is all easy to use. Visit http://www. dovepress.com/testimonials.php to read real quotes from published authors. 